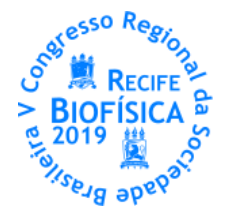

\title{
MARCADORES DE SUPERFÍCIE PARA CÉLULAS DE LEUCEMIAS MIELOBLÁSTICAS: UMA PROPOSTA ATRAVÉS DA MICROSCOPIA DE FORÇA ATÔMICA
}

\author{
Ruana Cardoso Lima ${ }^{1 *}$, Rossy-Eric Pereira Soares, Francisco Franciné Maia Jr. ${ }^{3}$, Alan Silva de Menezes ${ }^{1}$, Erivelton \\ Façanha da Costa ${ }^{4}$, Luciana Magalhães Rebelo Alencar ${ }^{1}$
}

${ }^{1}$ Central Multiusuário de Pesquisa em Nanoestruturas e Biossistemas, UFMA;

${ }^{2}$ Laboraório de Genética e Biologia Molecular, UFMA;

${ }^{3}$ Departamento de Ciências Naturais, Matemática e Estatística, UFERSA

${ }^{4}$ Instituto Federal de Educação Ciência e Tecnologia da Bahia IFBA, Campus Irecê..*ruanalima1@gmail.com

\begin{abstract}
INTRODUÇÃO
0 estudo das propriedades mecânicas e ultraestruturais das células é de extrema importância para entender sua organização e suas funções. Observar padrões mecânicos em células saudáveis e alterações desses padrões em células acometidas por doenças, nos oferece um marcador mecânico para detecção e compreensão de tais doenças. 0 presente trabalho tem justamente este objetivo: estudar a mecânica dos leucócitos e encontrar um marcador mecânico para leucemias utilizando a Microscopia de Força Atômica (AFM).

A leucemia mieloide afeta os mieolocitos, que são os precursores de alguns tipos de leucócitos. Os leucócitos (ou glóbulos brancos do sangue) desempenham um papel fundamental no sistema imunológico, ou seja, proteção do organismo contra doenças, inflamação dos tecidos, cicatrização de feridas e outros processos fisiológicos e patológicos. Observar as propriedades mecânicas dos leucócitos é crucial para o entendimento do seu papel enquanto célula sanguínea e imunológica, como, por exemplo, a sua deformação durante a liberação da medula óssea, seu movimento e deformação nos vasos sanguíneos, diapedese ${ }^{1}$, deformação e adesão durante a fagocitose, entre outras atividades leucocitárias que estão intimamente ligadas às suas características mecânicas (Schmid-Schönbein et al. 1981). Os leucócitos abrangem cinco tipos de células que diferem consideravelmente entre si. Os que apresentam grânulos são chamados de granulócitos e abrangem os neutrófilos, basófilos e eosinófilos (Fig. 1). Leucócitos sem grânulos são chamados mononucleares ou agranulócitos e incluem linfócitos e monócitos. Assim, podemos distinguir entre essas células de acordo com sua forma ou tamanho, a presença de grânulos no citoplasma e o número de lobos no núcleo. Os lobos são a parte mais substancial do núcleo e filamentos finos os conectam uns aos outros. (Hoggatt and Pelus 2013).
\end{abstract}

A leucemia é um tipo de câncer que afeta a produção das células sanguíneas resultando na proliferação de células anormais. As leucemias podem ser crônicas e agudas.

Neste trabalho, analisamos leucemias agudas do tipo mieloblástica (LMA), que afetam a linhagem mielóide e resultam no aumento de mieloblastos anomalos, o que causa a ruptura da hematopoese normal e subsequente falência da medula óssea. A Leucemia Mielomonocítica Aguda (LMMA) e a Leucemia Promielocítica Aguda (LPA) são dois subtipos da LMA.

Para células vivas, a técnica de obtenção de dados e imagens deve ser a menos invasiva possível. A Microscopia Ótica parece ser a mais adequada. No entanto, a maioria das células são transparentes e são da ordem de micrômetros e até nanômetros.
Essas características se põem como uma limitação, pois o limite de difração é aproximadamente $0.2 \mu \mathrm{m}$ e células transparentes não apresentam contraste, exceto quando são tingidas artificialmente, o que pode causar alteração na estrutura da célula (Chicea et al. 2010).

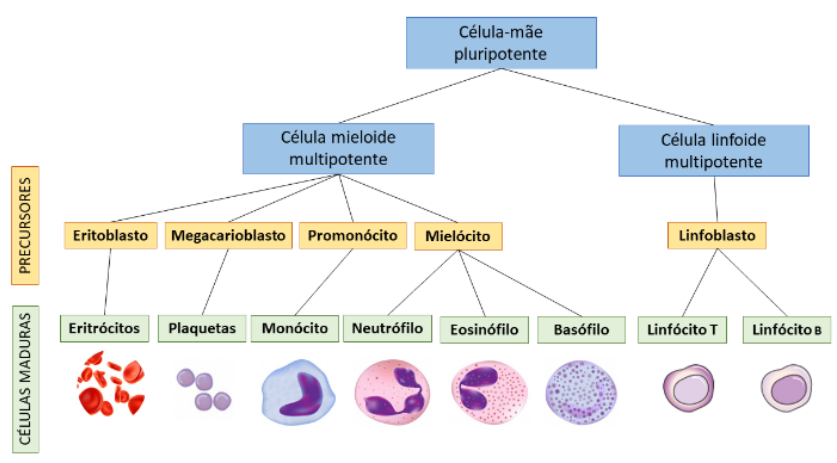

Figura 1. Esquema ilustrativo resumido da diferenciação hematopoiética.

A Microscopia de Força Atômica é uma técnica assertiva para obtenção de dados e imagens de sistemas biológicos, pois consegue fazer medidas em escala molecular e não depende da luz visível, mas sim das interações atômicas entre a amostra e a ponta da sonda. Muitas propriedades do material podem ser determinadas com técnicas de AFM, incluindo atrito, adesão, deformação, elasticidade, dissipação, forças magnéticas, viscoelasticidade, potencial de superfície, entre outras. Sabe-se que qualquer alteração na função celular induzida por um estado de doença pode modificar propriedades biomecânicas das células (Rebêlo et al. 2014), por exemplo, doenças como artrite, asma, malária e anemia falciforme, que são caracterizadas pelo enrijecimento celular, acarretando na dificuldade de tais células individualmente de transporem, por exemplo, vasos capilares, que possuem diâmetros micrométricos, enquanto que células tumorigênicas são caracterizadas pela redução de seu módulo de Young (dependendo do substrato sobre o qual se encontram) e também redução de seu módulo viscoso, possibilitando, dependendo da agressividade do câncer, a propagação das células carcinogênicas, divisão celular e metástase celular (Rebelo et al. 2014).

A técnica de AFM também já foi utilizada para caracterização de alguns processos celulares, tais como crescimento celular, exocitose e endocitose (You et al. 2000). Por isso, a Microscopia de Força Atômica se torna a ferramenta ideal para estudar a 
complexidade física dos sistemas biológicos. Ela é uma técnica de microscopia de alta resolução, chegando à escala atômica em amostras duras e à escala molecular em amostras macias, como é o caso de células e tecidos (Chang et al. 2012).

Neste trabalho, foi feito o estudo da adesão, da ultraestrutura, da deformação e da dissipação de leucócitos saudáveis e blastos de origem leucêmica através dos dados obtidos pelo microscópio de força atômica.

\section{MATERIAIS E MÉTODOS}

Utilizou-se células do sangue de doadores saudáveis e de pacientes com LMA. As amostras de LMA foram obtidas através de parceria com o Centro de Hemoterapia e Hematologia do Estado do Maranhão - HEMOMAR e com o Laboratório Cedro. Esfregaços de sangue periférico foram feitos com o auxílio de capilares com heparina sobre lâminas circulares de $13 \mathrm{~mm}$ de diâmetro, compatíveis com o porta-amostras do AFM. Todas as amostras foram mantidas sob refrigeração entre a coleta e os esfregaços. Após a realização dos esfregaços, as medidas foram realizadas no menor tempo possível. As medidas foram realizadas de acordo com o esquema mostrado na Fig. 2.

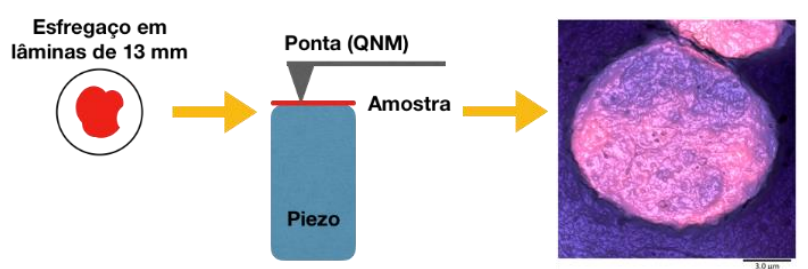

Figura 2. Sequência de medidas dos leucócitos para este trabalho. Esfregaço seguido de caracterização no AFM pelo modo Quantitative Nanomechanics e posterior análise dos resultados.

As amostras foram analisadas em um Microscópio de Força Atômica, modelo MultiMode 8 da Bruker, no modo Peak Force Quantitative Nanomechanics, com resolução de 512 samples/line e Scan Rate de $0.501 \mathrm{~Hz}$. A sonda utilizada foi de modelo ScanasystAir (Bruker), feita de Nitreto de Silício e com constante de mola medida experimentalmente pelo método de ruído térmico de valor de $0,4929 \mathrm{~N} / \mathrm{m}$.

Para o cálculo da adesividade das amostras, é observado que, durante a retração do cantilever, este sofre uma deflexão negativa até que sua força total supere as forças de adesão, perdendo o contato com a superfície da amostra. 0 ponto em que a força de adesão entre a ponta e a superfície da amostra atinge o seu valor máximo é aquele que corresponde ao ponto de mínimo de deflexão. Esse processo se repete sobre toda a superfície da amostra gerando um mapa de forças adesivas.

Usando essas características gerais, a adesividade das amostras a que foram analisadas neste projeto pode ser deduzida qualitativamente de duas diferentes formas: i) a força máxima de adesão entre a ponta e a amostra e ii) calculando o trabalho realizado pelas forças adesivas. 0 trabalho é obtido através do cálculo da área da curva de deflexão/deslocamento em sua porção negativa de deflexão (porção que corresponde às forças adesivas Fig.3).

Nos mapas de adesão obtidos, os contrastes são compostos utilizando a força máxima de adesão entre a ponta e a superfície da amostra.

Os valores de adesão foram calculados usando a deflexão negativa das curvas de força que representam um ciclo de aproximação e retração do cantilever em relação à superfície da amostra. Durante a retração, o cantilever sofre uma deflexão negativa até que sua força de saída, entre a ponta e a superfície da amostra, exceda as forças de adesão, perdendo contato com a amostra. 0 ponto no qual a força de adesão entre a sonda e a amostra é máxima corresponde ao ponto mínimo de deflexão.

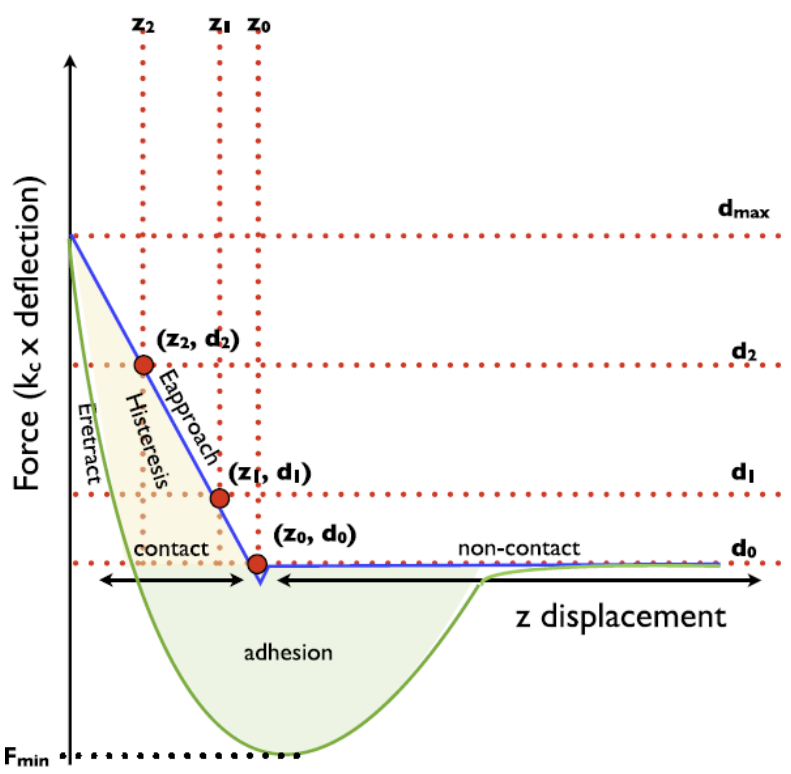

Figura 3: Figura esquemática de uma típica curva de deflexão/deslocamento adquirida em uma amostra macia, exibindo uma histerese entre as curvas de aproximação e retração, além de uma região de adesividade. $O$ ajuste destas curvas em um dado intervalo de deflexão (d1, d2), com modelo de Hertz, proporciona um valor estimado do módulo elástico da amostra. A partir da histerese, pode-se empregar modelos matemáticos específicos para determinar a viscosidade aparente de amostras macias, como uma célula.

Nos dados de AFM, quando a análise de rugosidade é aplicada a uma imagem, os valores estatísticos são calculados de acordo com as alturas de cada pixel na imagem. Há dois valores que são levados em consideração: $R_{\alpha}$ e $R_{q}$.

$R_{\alpha}$ é o valor de rugosidade média da superfície. A rugosidade média é apenas o perfil médio absoluto, não fazendo distinção entre picos e vales. A expressão utilizada para o cálculo dos valores de $R_{a}$ é:

$R_{a}=\frac{1}{N} \sum_{j=1}^{M} Z_{j}$

$R_{\text {q }}$ é o valor da raiz quadrada média da rugosidade e é uma função que leva em consideração o quadrado das medidas. $0 R_{q}$ é mais sensível a picos e vales do que a rugosidade média, proporcional ao quadrado da altura tomado em seu cálculo, de acordo com a equação abaixo:

$R_{\mathrm{q}}=\sqrt{\frac{\sum Z_{i}^{2}}{N}}$

Em cada célula investigada neste estudo, foi realizada uma imagem com dimensão lateral de 7 micrometros. Sobre esta área foram calculados os valores de $R_{\text {qq }}$ e $R_{a}$.

Em cada tipo de amostra: grupo controle, LMA, LMMA e LPA, foram analisadas 5 células e, para cada célula, foram feitas varreduras de $30,15,5$ e 2 micrometros de dimensão lateral, para preservar a resolução e acessar a ultraestrutura as membranas das mesmas. Para as análises dos dados de topografia, rugosidade, adesão e propriedades mecânicas em geral, utilizaram-se os softwares NanoScope Analysis e Gwyddion. Os resultados são apresentados a seguir. 


\section{RESULTADOS E DISCUSSÃO}

Os dados obtidos através de AFM mostram, à primeira vista, a diferenciação topográfica das células, sendo possível diferenciar a estrutura do núcleo, quantidade de grânulos e tamanho. Comparando as células saudáveis com as células leucêmicas, observa-se que as células mieloblásticas apresentam menor escala de altura, como pode-se notar nas imagens apresentadas na Fig 5. Nas imagens AFM, os blastos apresentaram também uma textura muito distinta das células de doadores saudáveis, com maior número de orifícios na superfície. Tal característica deve-se à grande liberação de conteúdo citoplasmático a que os leucócitos lançam mão para a execução de suas funções no sistema imunológico, como liberação de histamina em processos alérgicos e inflamatórios, por exemplo. Os leucócitos granulócitos, como é o caso do eosinófilo, visualizado na Fig 5 , contêm enzimas que danificam ou digerem patógenos e liberam mediadores inflamatórios na corrente sanguínea.

As imagens de adesão (Fig. 4 a e b) mostram uma grande diferença de escala entre as células saudáveis (cuja escala indica uma variação de $567,1 \mathrm{mV}$ ) e os blastos (cuja escala indica uma variação de $1014,5 \mathrm{mV}$ ). Pode-se observar que a diferença na adesão sobre a célula leucêmica é muito maior que no eosinófilo saudável. No entanto, para os dois casos, a adesão não se limita à superfície da célula. Há, na região circunvizinha às células, áreas de adesão acentuada.
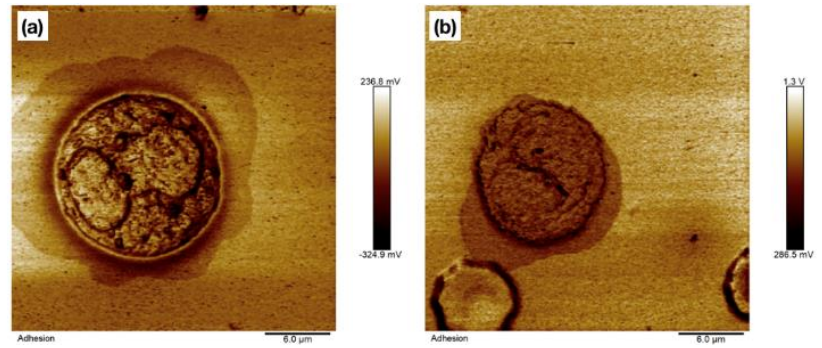

Figura 4. Imagem de adesão comparando (a) eosinófilo sadio e (b) célula LMA. Escala de adesão mostra diferença marcante entre células sadias e de portadores de leucemias.

Por muito tempo, a ideia de que a perda de adesão leva à metástase do câncer tem sido considerada um paradigma. Esse resultado corrobora com a recente mudança desse paradigma (Gruszka et al. 2019). Como pode-se observar na Fig. 6, as células leucêmicas possuem uma adesão consideravelmente mais alta do que as células sadias. Vários fatores causam o aumento da adesão de células leucêmicas em comparação aos leucócitos saudáveis. Essa crescente adesão tem grandes consequências para o tratamento da leucemia, como evitar a apoptose das células doentes, resistência ao sistema imunológico e à quimioterapia, o que consequentemente causa a contínua proliferação dos blastos (Becker 2012). As propriedades de adesão e mecanobiologia das células leucêmicas estão relacionadas ao seu microambiente.

A rugosidade da superfície está relacionada com o funcionamento da célula e há uma diminuição na rugosidade da membrana, anteriormente já observada, em células de amostras patológicas (Yeow, Tabor, and Garnier 2017). Os dados aqui apresentados corroboram com tais estudos. Pelo diagrama apresentado na Fig. 7, é possível observar que a rugosidade das células leucêmicas está bem abaixo da rugosidade dos leucócitos saudáveis.
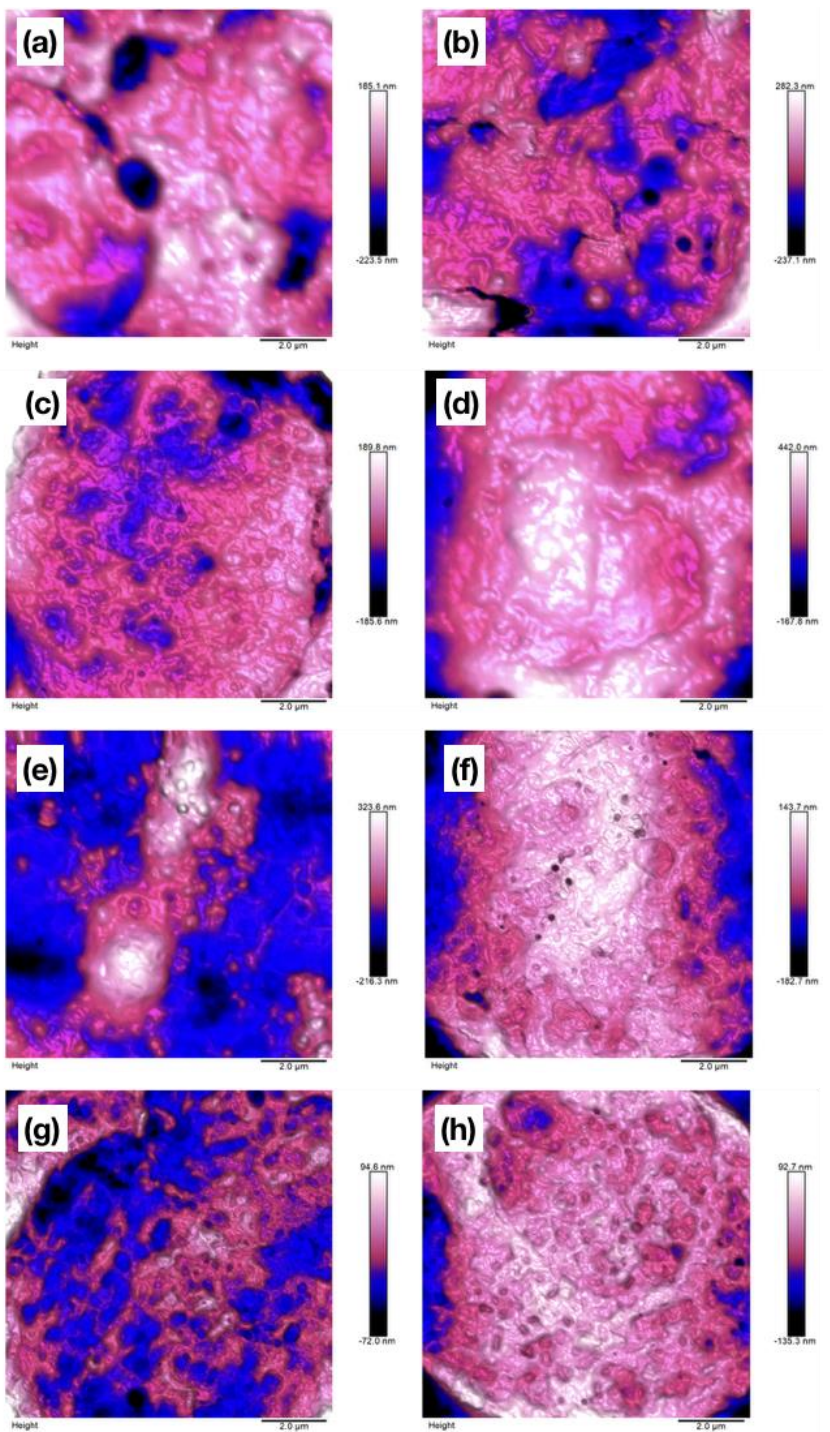

Figura 5. Imagem topográfica de diferentes tipos de leucócitos saudáveis e dos blastos leucêmicos. (a) eosinófilo, (b) basófilo (c) linfócito (d) neutrófilo bastão, (e) neutrófilo segmentado, (f) LMMA (g) LMA (h) LPA

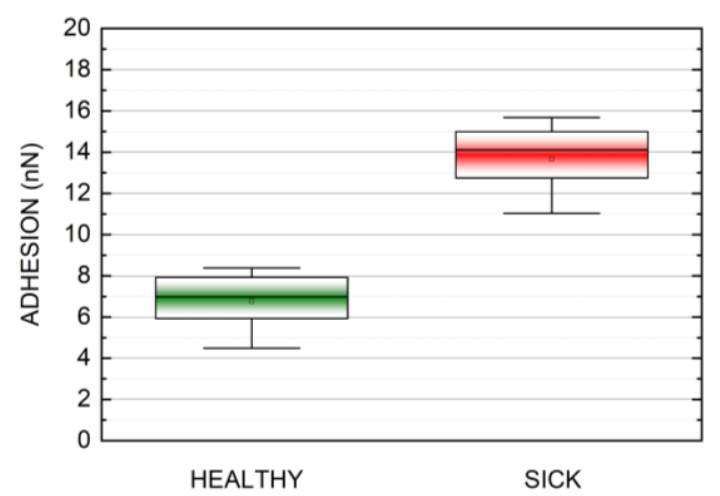

Figura 6. Diagramas de caixa comparando os valores de adesão entre os leucócitos saudáveis e os portadores de leucemia. Dentro de cada caixa, temos o $2^{\circ}$ e o $3^{\circ}$ quartil, na qual a linha horizontal e o símbolo representam, respectivamente, a mediana e a média. Os fios de bigodes (ou whiskers), que é a linha vertical com duas linhas horizontais indicando os limites inferior e superior, mostram o intervalo entre $10 \%$ e $90 \%$ dos valores das amostras. 

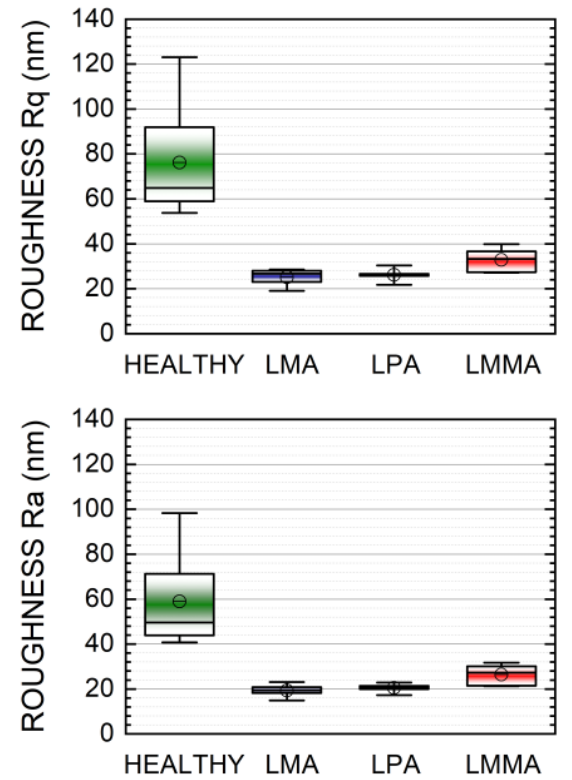

Figura 7. Diagrama de caixa mostrando a diferença entre os valores de rugosidade dos leucócitos saudáveis e as células leucêmicas.

É perceptível também a distribuição dos valores de rugosidade dos leucócitos, ou seja, há flutuação em tais valores, haja vista que cada tipo de leucócito apresenta granulação específica, como observado na Fig. 8 para um basófilo. É possível notar que os leucócitos apresentam maior rugosidade, em parte devido à sua granulação, e em parte devido à estrutura afetada nas células cancerosas.

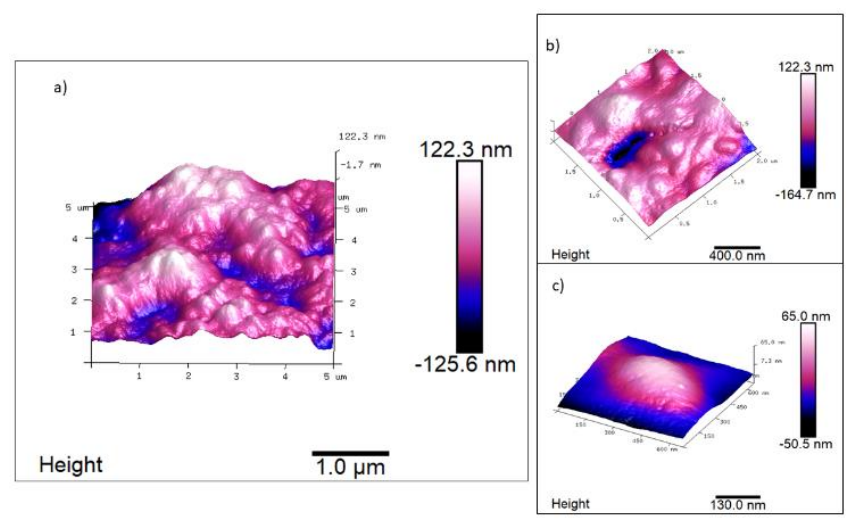

Figura 8. Imagem topográfica de um basófilo, evidenciando os grânulos na membrana (a) varredura de 5 mm (b) grânulo único, numa varredura de 2 m e c) varredura de 664.1 $\mathrm{nm}$.

\section{CONCLUSÕES}

0 entendimento da biomecânica das células blásticas de LMA, utilizando AFM, pode trazer novas informações quanto ao mecanismo de adesão, rugosidade e interações celulares mecânicas que favorecem o desenvolvimento da LMA, ou mesmo o desfecho clínico dessa neoplasia. Observa-se que as células leucêmicas apresentam alta adesividade em comparação aos leucócitos sadios. Os dados obtidos sugerem futuras investigações sobre métodos de diminuir a adesão dessas células e, consequentemente, a metástase e resistência ao tratamento. Foi possível notar também a diferença na rugosidade das células estudadas. Como apontado pela literatura, a rugosidade das células neoplásicas mostrou-se muito menor do que a rugosidade dos leucócitos saudáveis.
Finalmente, os resultados aqui apresentados podem lançar luz à novos meios de abordagem no tratamento da leucemia mieloide aguda.

\section{REFERÊNCIAS}

Becker, Pamela S. 2012. "Dependence of Acute Myeloid Leukemia on Adhesion within the Bone Marrow Microenvironment." The Scientific World Journal 2012:1-4.

Chang, Kai-Chih, Yu-Wei Chiang, Chin-Hao Yang, and Je-Wen Liou. 2012. "Atomic Force Microscopy in Biology and Biomedicine." Tzu Chi Medical Journal 24(4):162-69.

Chicea, D., B. Neamtu, R. Chicea, and L. M. Chicea. 2010. "The Application of AFM for Biological Samples Imaging." Digest Journal of Nanomaterials and Biostructures 5(4):1015-22.

Gruszka, Alicja, Debora Valli, Cecilia Restelli, and Myriam Alcalay. 2019. "Adhesion Deregulation in Acute Myeloid Leukaemia." Cells 8(1):66.

Hoggatt, J. and L. M. Pelus. 2013. "Hematopoiesis." in Brenner's Encyclopedia of Genetics: Second Edition.

Rebêlo, L. M., J. S. De Sousa, J. Mendes Filho, J. Schäpe, H. Doschke, and M. Radmacher. 2014. "Microrheology of Cells with Magnetic Force Modulation Atomic Force Microscopy." Soft Matter 10(13):2141-49.

Rebelo, L. M., J. S. De Sousa, T. M. Santiago, and J. Mendes Filho. 2014. "Correlating Cell Morphology and Viscoelasticity to Investigate Diseases with Atomic Force Microscopy." Microscopy: Advances in Scientific Research and Education 141-52.

Schmid-Schönbein, G. W., K. L. Sung, H. Tözeren, R. Skalak, and S. Chien. 1981. "Passive Mechanical Properties of Human Leukocytes." Biophysical Journal 36(1):243-56.

Yeow, Natasha, Rico F. Tabor, and Gil Garnier. 2017. "Atomic Force Microscopy: From Red Blood Cells to Immunohaematology." Advances in Colloid and Interface Science 249:149-62.

You, Hong Xing, Joan M. Lau, Shengwen Zhang, and Lei Yu. 2000. "Atomic Force Microscopy Imaging of Living Cells: A Preliminary Study of the Disruptive Effect of the Cantilever Tip on Cell Morphology." Ultramicroscopy 82(1-4):297-305. 